Article

\title{
Molecular Modelling of the Ni(II)-Responsive Synechocystis PCC 6803 Transcriptional Regulator InrS in the Metal Bound Form
}

\author{
Elia Barchi and Francesco Musiani *D \\ Laboratory of Bioinorganic Chemistry, Department of Pharmacy and Biotechnology, University of Bologna, \\ Viale G. Fanin 40, I-40127 Bologna, Italy; elia.barchi91@gmail.com \\ * Correspondence: francesco.musiani@unibo.it; Tel.: +39-051-209-6236
}

Received: 24 May 2019; Accepted: 20 June 2019; Published: 21 June 2019

check for updates

\begin{abstract}
InrS (internal nickel-responsive sensor) is a transcriptional regulator found in cyanobacteria that represses the transcription of the nickel exporter $\mathrm{NrsD}$ in the apo form and de-represses expression of the exporter upon $\mathrm{Ni}$ (II) binding. Although a crystal structure of apo-InrS from Synechocystis PCC 6803 has been reported, no structure of the protein with metal ions bound is available. Here we report the results of a computational study aimed to reconstruct the metal binding site by taking advantage of recent X-ray absorption spectroscopy (XAS) data and to envisage the structural rearrangements occurring upon $\mathrm{Ni}(\mathrm{II})$ binding. The modelled $\mathrm{Ni}(\mathrm{II})$ binding site shows a square planar geometry consistent with experimental data. The structural details of the conformational changes occurring upon metal binding are also discussed in the framework of trying to rationalize the different affinity of the apo- and holo-forms of the protein for DNA.
\end{abstract}

Keywords: InrS; nickel-dependent transcriptional regulators; molecular modelling

\section{Introduction}

Nickel is an essential element for the metabolism of various pathogenic bacteria and is also used by plants, fungi, plants, and single-cell eukaryotic organisms, but not by higher animals such as humans [1]. This peculiarity can be exploited against the phenomenon of antibiotic resistance in pathogenic bacteria. Indeed, eight out of 12 dangerous microorganisms recently identified by the World Health Organization use nickel for their survival [2]. Consequently, the understanding of the molecular mechanisms underlying the use of this metal and regulating the genic expression of nickel-metabolism-related proteins is of fundamental importance.

In cyanobacteria, nickel ions are directly bound to urease and hydrogenases or through the tetrapyrrole ring of coenzyme $\mathrm{F}_{430}$; several other nickel-binding proteins are deputed to nickel import, trafficking and export [3]. Among these proteins, the internal nickel-responsive sensor (InrS) is a transcriptional regulator exclusively found in cyanobacteria [4-6]. It belongs to the resistance to cobalt and nickel repressor (RcnR)/copper-sensitive operon repressor (CsoR) family of transcriptional regulators [7], consisting in disc-shaped all $\alpha$-helical homo dimer $(\alpha \beta)$ of dimers $\left(\alpha \beta / \alpha^{\prime} \beta^{\prime}\right)$ formed by three-helix bundles monomers (Figure S1) [4,8-10]. With the exception of the formaldehyde-sensing transcriptional regulator (FrmR) [11,12] and of the CsoR-like sulphur transferase repressor (CstR, where the binding to the operator is inhibited by the oxidation of an inter-subunit cysteine pair by sulphite) $[13,14]$, all the characterized members of this family are metal-ion sensors (Figure 1 and Table S1) $[5,7,10]$.

In the case of InrS, the function of the protein is to repress the expression of a nickel exporter $(\mathrm{NrsD})$ and to enhance the expression of proteins involved in nickel import when the concentration 
of intracellular $\mathrm{Ni}(\mathrm{II})$ is too low by forming a stable protein-DNA complex [5,6,15]. Competition experiments conducted on InrS from Synechocystis PCC 6803 (SyInrS), using the Ni(II) chelating ligands NTA, EGTA and EDTA, estimated a dissociation constant of SyInrS for Ni(II) in the sub-picomolar range $\left(K_{d}=2 \times 10^{-14} M\right)$ [4]. Calorimetric experiments conducted on the same protein, but in the absence of possible artefacts due to the presence of the exogenous competitors, revealed instead dissociation constants for $\mathrm{Ni}(\mathrm{II})$ in the nanomolar/micromolar range. In particular, a $2+2$ binding mode for SyInrS was observed, with the two binding events featuring dissociation constants of $70 \mathrm{nM}$ and $4.5 \mathrm{mM}$, respectively [6]. The formation of a Ni(II)-SyInrS complex decreases the DNA affinity of the protein and consequently de-represses the expression of the $n r s D$ gene [16]. However, in the absence of a structural comparison involving the apo- and holo-forms of InrS, a rationalization for the function of this Ni-sensor cannot be achieved.

An initial study of the Ni(II)-binding site in SyInrS performed by using electronic absorption spectroscopy revealed that $\mathrm{Ni}$ (II) ions bind in a four-coordinate planar geometry comprising at least one cysteine ligand [4]. The alignment between the SyInrS sequence and the other CsoR/RcnR family members revealed that the canonical $\mathrm{W}-\mathrm{X}-\mathrm{Y}-\mathrm{Z}$ fingerprint, used to characterize the first coordination shell residues [8,9], corresponds to His21, Cys53, His78, and Cys82 in SyInrS (Figure 1). A subsequent mutagenesis study confirmed the roles of the latter three residues in $\mathrm{Ni}(\mathrm{II})$ binding [16], while His21 has been recently confirmed as the fourth $\mathrm{Ni}$ (II) ligand both through mutagenesis [17] and X-ray absorption spectroscopy (XAS) data [18]. The latter study, which investigated both $\mathrm{Ni}(\mathrm{II})$ and $\mathrm{Cu}$ (II) bound SyInrS, also confirmed the presence of a planar four-coordinate $\left[\mathrm{Ni}(\mathrm{His})_{2}(\mathrm{Cys})_{2}\right]$ site and provided $\mathrm{Ni}(\mathrm{II})$-ligands interatomic distances [18].

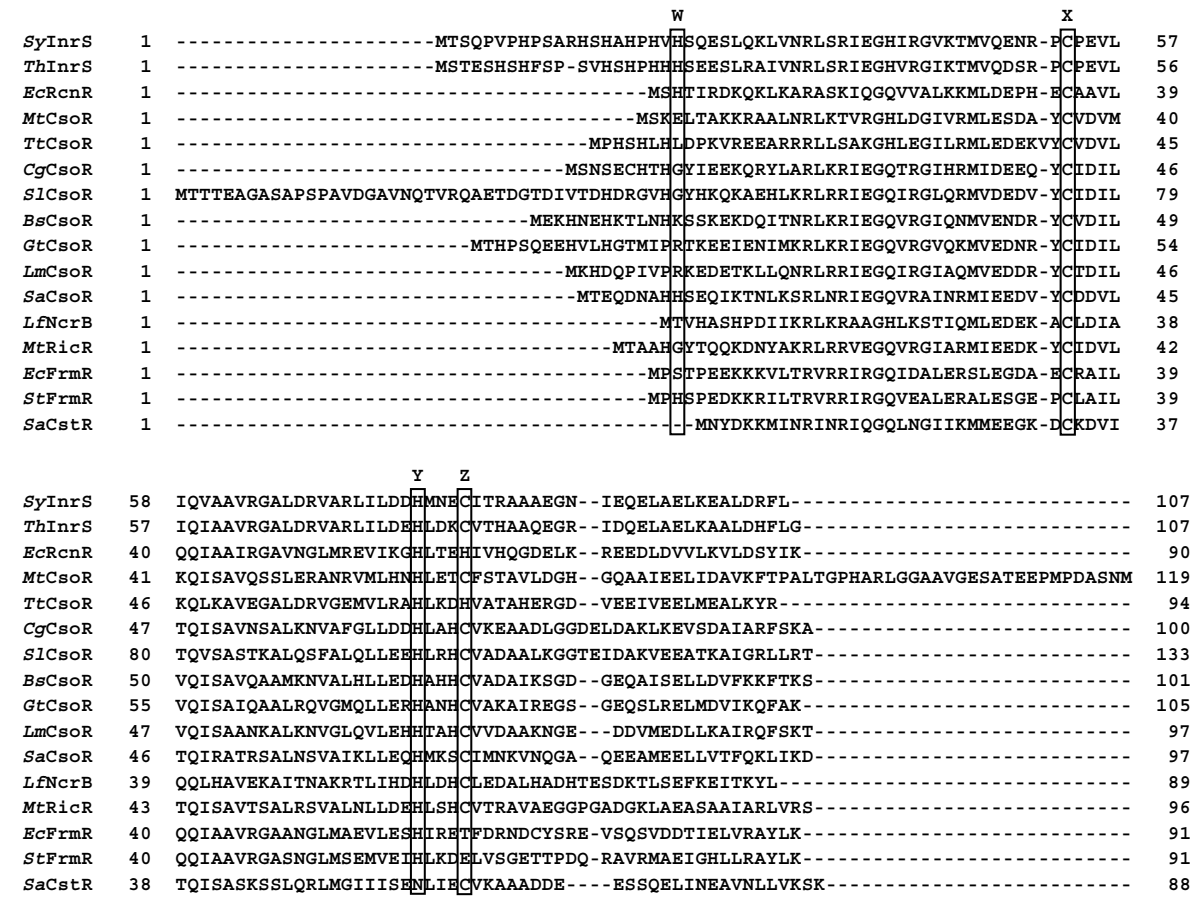

Figure 1. PROMALS3D [19] multiple sequence alignment of the known members of the RcnR/CsoR family. Synechocystis PCC 6803 InrS, SyInrS; Thermosynechococcus sp. NK55a InrS, ThInrS; Escherichia coli RcnR, EcRcnR; Mycobacterium tuberculosis CsoR, MtCsoR; Thermus thermophilus CsoR, TtCsoR; Corynebacterium glutamicum CsoR, CgCsoR; Streptomyces lividans CsoR, SlCsoR; Bacillus subtilis CsoR, BsCsoR; Geobacillus thermodenitrificans CsoR, GtCsoR; Listeria monocytogenes CsoR, LmCsoR; Staphylococcus aureus CsoR, SaCsoR; Leptospirillum ferriphilum NcrB, Lf NcrB; Mycobacterium tuberculosis RicR, MtRicR; Escherichia coli FrmR, EcFrmR; Salmonella typhimurium (strain SL1344) FrmR, StFrmR; Staphylococcus aureus NCTC 8325, SaCsrT. The CsoR/RcnR W-X-Y-Z fingerprint residues have been highlighted by black boxes. 
The recently solved crystal structure of apo-SyInrS (Figure 2a) showed the typical fold of the RcnR/CsoR family and the proximity of Cys53, His78, and Cys82, strengthening the hypothesis of their role in the $\mathrm{Ni}$ (II) binding site [17]. The metal binding site (Figure 2b) should thus be formed by Cys53, located at the beginning of helix $\alpha 2$ from one monomer and located in the vicinity of His78 and Cys82 (at the C-term of helix $\alpha 2$ ) from the adjacent monomer. On the other hand, His21 is located on an unstructured region at the beginning of helix $\alpha 1$, apparently far from the other three residues, but it can be envisioned that it can complement them through a conformational rearrangement of the N-terminal region.
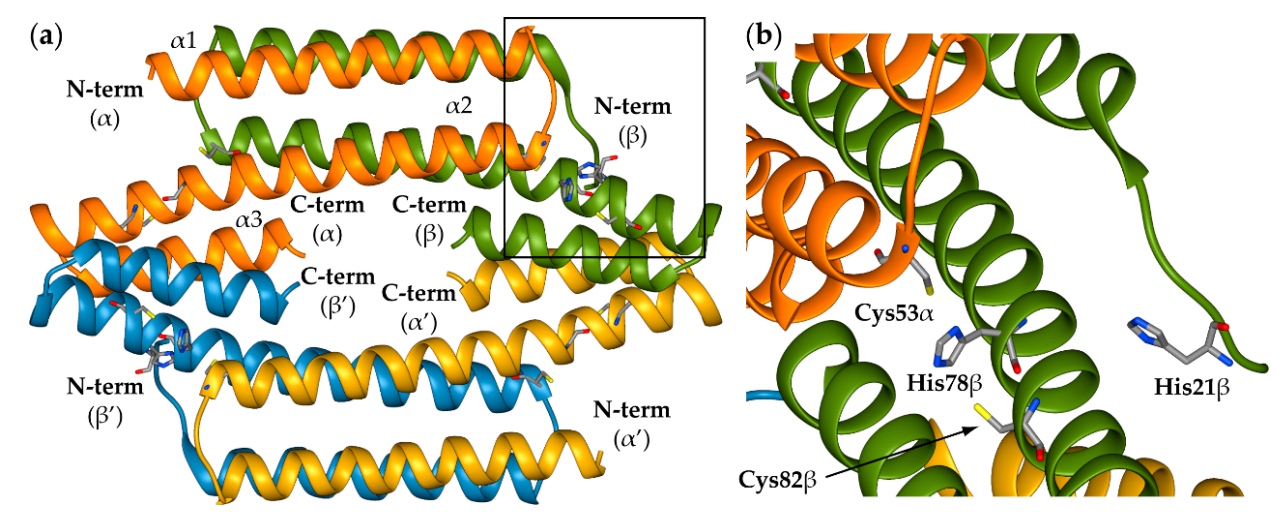

Figure 2. (a) Ribbon diagram of SyInrS crystal structure (PDB id: 5FMN [17]). Chains $\alpha, \beta, \alpha^{\prime}$, and $\beta^{\prime}$ are coloured in orange, green, yellow, and light blue, respectively. (b) Detail of the putative metal binding region [black square in panel (a)]. Proposed Ni(II) binding residues are reported as sticks coloured accordingly to the atom type.

In addition to a lack of structural information for the Ni(II) bound SyInrS, the structural details of the protein-DNA interaction of proteins belonging to the CsoR/RcnR family are also missing. Nevertheless, Streptomyces lividans CsoR (SlCsoR) binds the cognate DNA operator with a 2 SlCsoR: 1 DNA stoichiometry [20] and indirect structural models for CsoR:DNA operator binding have been proposed in the last few years in the case of Bacillus subtilis CsoR (BsCroR) [21] and SlCsoR [20]. Of all the members of this family, both CsoR and FrmR have been crystalized in both the ligand-free and -bound forms (see Figure S1 in Supplementary Materials). A comparison between the apo- and holo-FrmR structures revealed a conformational rearrangement in response to formaldehyde binding, which involves a translational movement of $\alpha$-helices $\alpha 1$ and $\alpha 2$ of one monomer, which slide across the equivalent helices on the other monomer by ca. $1.5 \alpha$-helical turns [12]. Similar conformational changes, involving $\alpha$-helix movement and rotation within the homo-tetramer assembly, were also observed in the case of SlCsoR [22] and Geobacillus thermodenitrificans (GtCsoR) [23]. This rearrangement causes the structure to compact and a rearrangement of the charges on the surface of the tetramers. Therefore, a similar behaviour can also be inferred for SyInrS. The aim of the present work is to gain structural information on the $\mathrm{Ni}(\mathrm{II})$-bound SyInrS through the use of molecular modelling techniques guided by all the available experimental data.

\section{Results and Discussion}

\subsection{Reconstruction of Apo-SyInrS N-terminal Region and Modelling of Holo-SyInrS}

In principle, $\mathrm{Ni}$ (II) binding to SyInrS could induce a conformational rearrangement similar to that observed for FrmR [12], even though it is not possible to exclude that only a negligible structural effect could be induced by metal binding. Thus we performed the modelling of the nickel binding site by starting from two SyInrS structures: (i) The crystal structure of tetrameric apo-SyInrS (PDB id: 5FMN [17]) and (ii) the model structure of tetrameric SyInrS in the putative Ni(II)-bound conformation. In the first case, the crystal structure of apo-SyInrS was used after the addition of three residues at the $\mathrm{N}$-terminal of chains $\alpha$ 
and $\alpha^{\prime}$ (namely His19, Val20 and the putative metal binding residue His21) that are missing in the crystal structure probably because of disorder. This reconstruction was carried out through homology modelling, using the atomic positions of the corresponding residues in chains $\beta$ and $\beta^{\prime}$, which are instead structurally well-defined in the same PDB file. For the model of apo-SyInrS in the holo conformation, the homology modelling technique was also used, but in this case the available crystal structures of $\mathrm{Cu}(\mathrm{I})$-bound $\mathrm{CsoR}$ from Mycobacterium tuberculosis and Geobacillus thermodenitrificans NG80-2 were used as templates (Figure S1, PDB id: 2HH7 [7] and 4M1P [8], respectively).

Figure 3 reports the results of the reconstruction of the missing protein portions of SyInrS in the apo conformation and of the modelling in the holo conformation (apo-SyInrS and holo-SyInrS hereafter, respectively, uniquely to the conformation of the protein and not referred to the metalation state). In the model of holo-SyInrS it was possible to include residues 13-18 at the N-terminal of each monomer. These residues were not present in the crystal structure of apo-SyInrS. In both cases the model structures were analysed by using the software PROCHECK [24] and QMEAN [25], with very satisfactory results ( $\geq 97.5 \%$ most favoured regions and $\leq 2.5 \%$ additional allowed regions). The general fold of the protein is the same regardless of the conformation, with each monomer made of three $\alpha$-helices and each dimer being formed by the interaction of the $\mathrm{N}$-terminal portion of helix $\alpha 2$ from each monomer. The dimer of dimers is then formed by the interaction of the C-terminal portion of $\alpha$-helix $\alpha 2$ and the entire $\alpha$-helix $\alpha 3$ from each monomer. In both conformations, the protein quaternary structure is disc-shaped with some subtle differences. The axis of inertia ellipsoid inscribing the structure of apo-SyInrS results in axes of $77.0 \AA, 60.2 \AA$ and $29.2 \AA$; similarly, values of $76.8 \AA, 65.8 \AA$ and $28.8 \AA$ were determined for holo-SyInrS (Figure S2). This indicates a significant increase (by ca. $6 \AA$ ), upon nickel binding, of the medium axis. This is caused by a movement of $\alpha$-helix $\alpha 1$ of each monomer, which slides along the facing helix on the interacting monomer by ca. $1.5 \alpha$-helical turns (coherently with the same conformational change observed in the case of FrmR [12]). Moreover, $\alpha$-helices $\alpha 1$ and $\alpha 2$ rotate by ca. 21 and 13 degrees around the tetramer vertical axis, respectively (Figure S3). The rearrangement of each dimer causes a consequent re-organisation of the interactions between $\alpha$-helices $\alpha 3$ at the dimer of dimers interface and a narrowing of the cavity at the centre of the structure. Finally, holo-SyInrS loses the biconcave shape observed in the apo form (see Figure 3, lower panels) and assumes the shape of a convex disk.
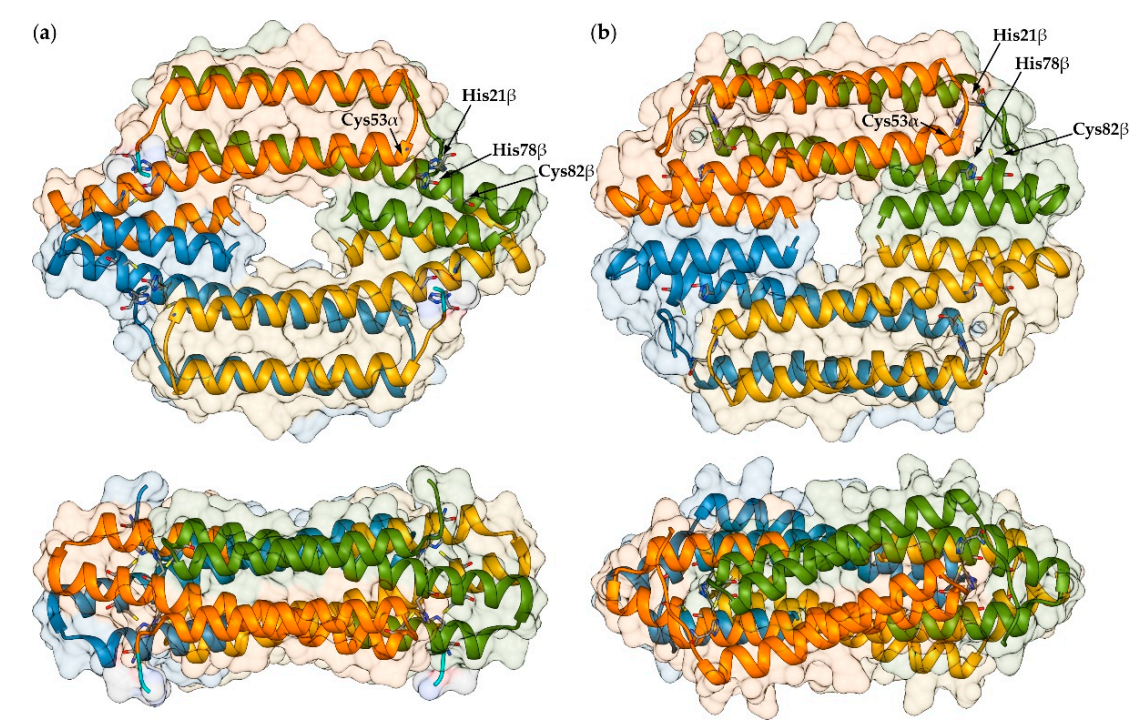

Figure 3. Ribbon diagram and molecular surface of apo-SyInrS (a) and holo-SyInrS (b). Chains $\alpha, \beta, \alpha^{\prime}$, and $\beta^{\prime}$ are coloured as in Figure 1. In panel (a), the reconstructed residues of chains $\alpha$ and $\alpha^{\prime}$ are in red. Proposed Ni(II) binding residues are reported as sticks coloured accordingly to the atom type. The orientations in the bottom panels are rotated by $90^{\circ}$ around the horizontal axis with respect to the orientations in the top panels. 
The molecular surface of the SyInrS tetramer is characterized by two positively charged regions on each side of the disk-shaped protein (Figure 4). The presence of such regions is due to the presence of residues Lys29, Arg32, and Arg35 ( $\alpha$-helix $\alpha 1)$ and Arg69 and Arg71 ( $\alpha 2)$ on the protein surface. The conformational change occurring upon transition from the apo to the holo form of SyIrnS causes a displacement of these positively charged regions toward the center of $\alpha$-helices $\alpha 1-2$. Moreover, in the holo conformation there are two negatively charged regions on each side of the disk formed by the SyInrS tetramer that are much more reduced in the apo form.
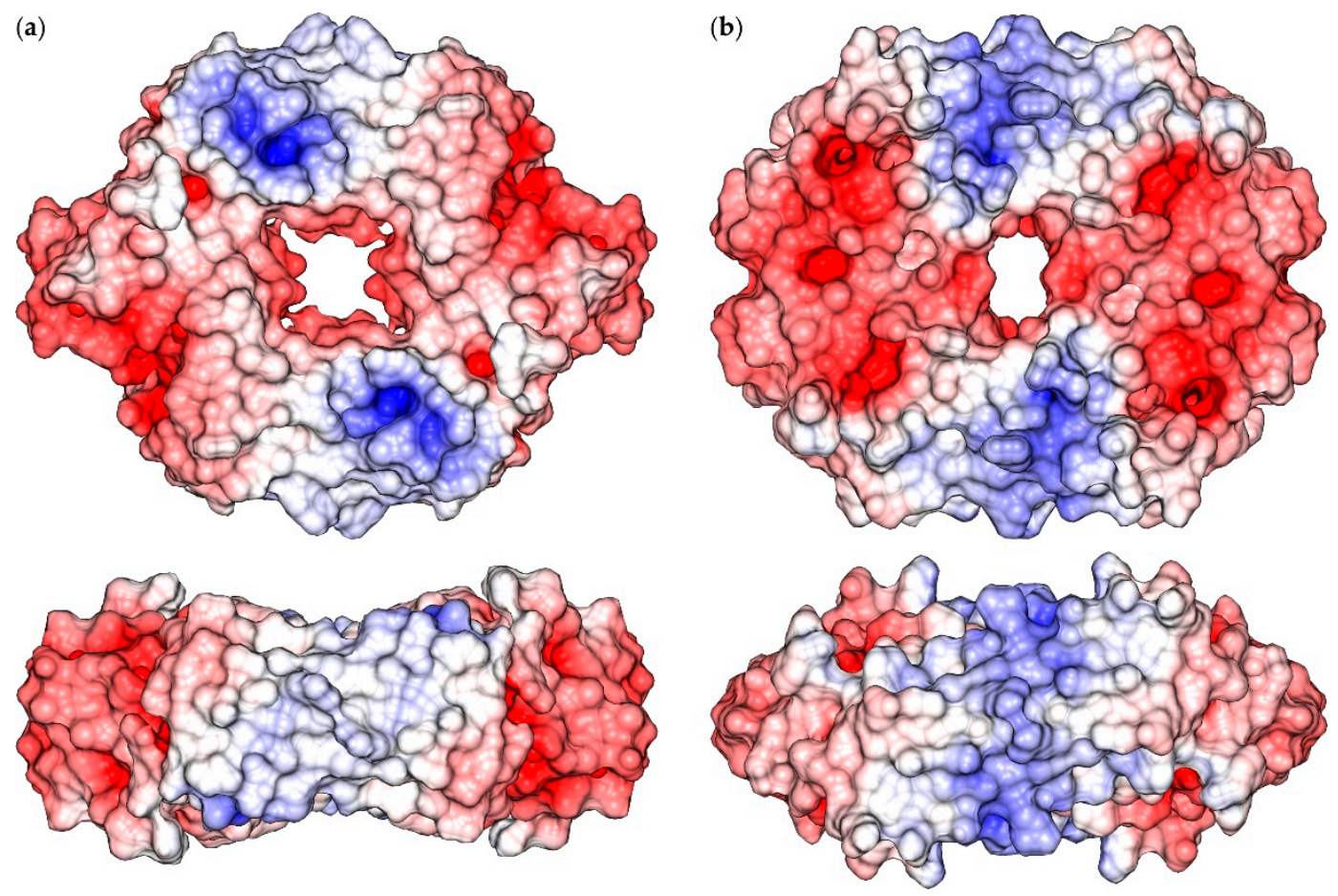

Figure 4. Molecular surface of apo-SyInrS (a) and holo-SyInrS (b). The surface is coloured according to the surface electrostatic potential calculated with APBS software [26]. The orientations in the bottom panels are rotated by $90^{\circ}$ around the horizontal axis with respect to the orientations in the top panels.

The intermolecular interactions occurring among the four monomers that make up the protein structure were analysed by using the PDBsum server $[27,28]$ and the results are reported in Table 1 . From the data, it appears that the apo-to-holo transition significantly increases the number of non-bonded contacts both in the $\alpha-\beta$ dimer and at the dimer of dimers $\left(\alpha-\beta^{\prime}\right)$ interface. On the other hand, the interaction surface, as well as the number of involved residues, increases at the dimer interface and decreases at the dimer of dimers interface. The significance of the changes observed in the case of hydrogen bonds and salt bridges are difficult to interpret due to the intrinsic errors involved in the homology modelling procedure.

Table 1. PDBsum analysis of the interaction between the SyInrS protein chains.

\begin{tabular}{ccccccc}
\hline Conformation & $\begin{array}{c}\text { Interacting } \\
\text { Monomers }\end{array}$ & $\begin{array}{c}\text { Interface } \\
\text { Residues }\end{array}$ & $\begin{array}{c}\text { Interface } \\
\text { Surface }\left(\AA^{2}\right)\end{array}$ & $\begin{array}{c}\text { Non-Bonded } \\
\text { Contacts }\end{array}$ & $\begin{array}{c}\text { Hydrogen } \\
\text { Bonds }\end{array}$ & $\begin{array}{c}\text { Salt } \\
\text { Bridges }\end{array}$ \\
\hline Apo & $\alpha-\beta\left(\alpha^{\prime}-\beta^{\prime}\right)$ & 22 & 1490 & 87 & 8 & 6 \\
& $\alpha-\beta^{\prime}\left(\alpha^{\prime}-\beta\right)$ & 17 & 952 & 55 & 5 & 2 \\
\hline \multirow{2}{*}{ Holo } & $\alpha-\beta\left(\alpha^{\prime}-\beta^{\prime}\right)$ & 30 & 1950 & 133 & 2 & 4 \\
& $\alpha-\beta^{\prime}\left(\alpha^{\prime}-\beta\right)$ & 13 & 670 & 78 & 0 & 2 \\
\hline
\end{tabular}




\subsection{Modelling of Ni(II) Bound Forms of SyInrS}

The inclusion of four $\mathrm{Ni}(\mathrm{II})$ ions (one per monomer) was performed through the application of a well-established protocol, already successfully used on another member of the RcnR/CsoR family: RcnR from Escherichia coli [29], and on UreG from Helicobacter pylori, a protein involved in the activation of the nickel-dependent enzyme urease [30]. In principle, each $\mathrm{Ni}$ (II) ion was constrained to the residues identified in previous studies [16] and by using the interatomic distances derived from the analysis of EXAFS data [18]. Additional angle and torsional restraints were added in order to ensure the correct orientation of the interacting residue with the $\mathrm{Ni}(\mathrm{II})$ ion (Table 2).

Table 2. Distances, angles, and dihedral constraints used in the modelling of Ni(II)-bound SyInrS. All constraints in the form mean \pm 1 standard deviation.

\begin{tabular}{|c|c|c|}
\hline \multicolumn{2}{|c|}{ Constrained Atoms } & Distance $(\AA ̊)$ \\
\hline \multicolumn{2}{|c|}{$\mathrm{Ni}(\mathrm{II})-\mathrm{His} 21(\mathrm{~N} \delta / \varepsilon)$} & $1.9 \pm 0.05$ \\
\hline \multicolumn{2}{|c|}{$\mathrm{Ni}(\mathrm{II})-\mathrm{His} 78(\mathrm{~N} \delta / \varepsilon)$} & $1.9 \pm 0.05$ \\
\hline \multicolumn{2}{|c|}{$\mathrm{Ni}(\mathrm{II})-\mathrm{Cys} 53(\mathrm{~S} \gamma)$} & $2.2 \pm 0.05$ \\
\hline \multicolumn{2}{|c|}{$\mathrm{Ni}(\mathrm{II})-\mathrm{His} 82(\mathrm{~S} \gamma)$} & $2.2 \pm 0.05$ \\
\hline Bonded Atoms & Constrained Atoms & Angle (Degrees) \\
\hline $\mathrm{Ni}(\mathrm{II})-\mathrm{Cys}(\mathrm{S} \gamma)$ & $\mathrm{Ni}(\mathrm{II})-\mathrm{Cys}(\mathrm{S} \gamma)-\mathrm{Cys}(\mathrm{C} \beta)$ & $109 \pm 5$ \\
\hline \multirow[t]{2}{*}{$\mathrm{Ni}(\mathrm{II})-\mathrm{His}(\mathrm{N} \delta)$} & $\mathrm{Ni}(\mathrm{II})-\mathrm{His}(\mathrm{N} \delta)-\mathrm{His}(\mathrm{C} \gamma)$ & $120 \pm 10$ \\
\hline & $\mathrm{Ni}(\mathrm{II})-\mathrm{His}(\mathrm{N} \delta)-\mathrm{His}(\mathrm{C} \varepsilon)$ & $120 \pm 10$ \\
\hline \multirow[t]{2}{*}{$\mathrm{Ni}(\mathrm{II})-\mathrm{His}(\mathrm{N} \varepsilon)$} & $\mathrm{Ni}(\mathrm{II})-\mathrm{His}(\mathrm{N} \varepsilon)-\mathrm{His}(\mathrm{C} \delta)$ & $120 \pm 10$ \\
\hline & $\mathrm{Ni}(\mathrm{II})-\mathrm{His}(\mathrm{N} \varepsilon)-\mathrm{His}(\mathrm{C} \varepsilon)$ & $120 \pm 10$ \\
\hline Bonded Atoms & Constrained Atoms & Dihedral (Degrees) \\
\hline \multirow[t]{2}{*}{$\mathrm{Ni}(\mathrm{II})-\mathrm{His}(\mathrm{N} \delta)$} & $\mathrm{Ni}(\mathrm{II})-\mathrm{His}(\mathrm{N} \delta)-\mathrm{His}(\mathrm{C} \varepsilon)-\mathrm{His}(\mathrm{N} \varepsilon)$ & $180 \pm 10$ \\
\hline & $\mathrm{Ni}(\mathrm{II})-\mathrm{His}(\mathrm{N} \delta)-\mathrm{His}(\mathrm{C} \gamma)-\mathrm{His}(\mathrm{C} \delta)$ & $180 \pm 10$ \\
\hline \multirow[t]{2}{*}{$\mathrm{Ni}(\mathrm{II})-\mathrm{His}(\mathrm{N} \varepsilon)$} & $\mathrm{Ni}(\mathrm{II})-\mathrm{His}(\mathrm{N} \varepsilon)-\mathrm{His}(\mathrm{C} \varepsilon)-\mathrm{His}(\mathrm{N} \delta)$ & $180 \pm 10$ \\
\hline & $\mathrm{Ni}(\mathrm{II})-\mathrm{His}(\mathrm{N} \varepsilon)-\operatorname{His}(\mathrm{C} \delta)-\mathrm{His}(\mathrm{C} \gamma)$ & $180 \pm 10$ \\
\hline
\end{tabular}

Considering that two of the four involved residues are histidines (His21 and His78) and that it is not possible to evince from the fitting of the EXAFS data which imidazole $\mathrm{N}$ atom interacts with nickel, four modelling calculations were carried out by starting from each protein conformation and involving all the possible combinations: $\mathrm{H} 21(\mathrm{~N} \varepsilon)-\mathrm{H} 78(\mathrm{~N} \delta), \mathrm{H} 21(\mathrm{~N} \delta)-\mathrm{H} 78(\mathrm{~N} \varepsilon), \mathrm{H} 21(\mathrm{~N} \delta)-\mathrm{H} 78(\mathrm{~N} \delta)$, and $\mathrm{H} 21(\mathrm{~N} \varepsilon)-\mathrm{H} 78(\mathrm{~N} \varepsilon)$. Most importantly, no restraints were added to constrain the coordination geometry around the metal ions. This was done in order to verify the possibility of the two possible conformations to bind nickel ions without further conformational rearrangements.

Tables 3 and 4 report the analysis conducted on the obtained models. First, the coordination geometry of the four $\mathrm{Ni}(\mathrm{II})$ ions was inspected by using the tool Metal Geometry included in the software UCSF Chimera [31] (Table 3). In particular, the root mean square deviation (RMSD) of the ligation set and metal ion with respect to their idealized positions was analysed when four ligands are considered. In the case of the metal bound models generated starting from apo-SyInrS, none of the resulting metal binding sites were in the experimentally determined square planar coordination geometry (see Figure S4). However, a distorted tetrahedral geometry was found when four ligands were considered in the analysis. Moreover, in order to satisfy the constraints included for the modelling of the metal site, in two cases the imidazole ring of His78 resulted in a highly distorted geometry. Also, in the case of the $\mathrm{H} 21(\mathrm{~N} \delta)-\mathrm{H} 78(\mathrm{~N} \varepsilon)$ and $\mathrm{H} 21(\mathrm{~N} \delta)-\mathrm{H} 78(\mathrm{~N} \delta)$ models generated starting from holo-SyInrS, the resulting coordination geometry was tetrahedral with different degrees of distortion (Figure S5). Of the two remaining models generated starting from holo-SyInrS, the most probable four-ligands coordination geometry was square planar and the distortion of the metal binding site from the ideal geometry was nearly identical $[0.29$ and $0.27 \AA$ for $\mathrm{H} 21(\mathrm{~N} \varepsilon)-\mathrm{H} 78(\mathrm{~N} \delta)$ and $\mathrm{H} 21(\mathrm{~N} \varepsilon)-\mathrm{H} 78(\mathrm{~N} \varepsilon)$, respectively] (Table 3 and Figure S5). 
Table 3. Analysis of the metal binding sites in the SyInrS Ni(II) bound models.

\begin{tabular}{|c|c|c|c|c|}
\hline \multirow{2}{*}{$\begin{array}{c}\text { Initial } \\
\text { Conformation } \\
\text { Model }\end{array}$} & \multicolumn{2}{|c|}{ Apo-SyInrS } & \multicolumn{2}{|c|}{ Holo-SyInrS } \\
\hline & $\begin{array}{l}\text { Best Coordination } \\
\text { Geometry }\end{array}$ & RMSD (Å) & $\begin{array}{c}\text { Best Conformation } \\
\text { Geometry }\end{array}$ & RMSD (Å) \\
\hline $\mathrm{H} 21(\mathrm{~N} \varepsilon)-\mathrm{H} 78(\mathrm{~N} \delta)$ & Tetrahedral & 0.54 & Square planar & 0.29 \\
\hline $\mathrm{H} 21(\mathrm{~N} \delta)-\mathrm{H} 78(\mathrm{~N} \varepsilon)$ & Tetrahedral & 0.23 & Tetrahedral & 0.53 \\
\hline $\mathrm{H} 21(\mathrm{~N} \delta)-\mathrm{H} 78(\mathrm{~N} \delta)$ & Tetrahedral & 0.65 & Tetrahedral & 0.36 \\
\hline $\mathrm{H} 21(\mathrm{~N} \varepsilon)-\mathrm{H} 78(\mathrm{~N} \varepsilon)$ & Tetrahedral & 0.39 & Square planar & 0.27 \\
\hline
\end{tabular}

In order to possibly discriminate between the two models resulting in a square planar metal binding site, the model structures were inspected by using the software PROCHECK [24] (Table 4). The parameters selected for this analysis were the number of residues localized in the four regions of the Ramachandran plot and the G-factor, a measure of how "normal" the stereochemical properties of the residues composing the protein were. The standards of "normality" have been derived from an analysis of 163 non-homologous, high-resolution protein chains chosen from structures solved by X-ray crystallography to a resolution of $2.0 \AA$ or better [24]. A low or a negative value of the $\mathrm{G}$-factor indicates that the protein chain has some residues in a low-probability conformation. From this analysis, the $\mathrm{H} 21(\mathrm{~N} \varepsilon)-\mathrm{H} 78(\mathrm{~N} \delta)$ model appears to have the best structural parameters.

Table 4. Structural analysis of the models of SyInrS binding nickel in square planar coordination geometry (see Table 3, see Tables S2 and S3 for the same analysis on all the models).

\begin{tabular}{|c|c|c|}
\hline \multirow{2}{*}{ Ramachandran Plot Region } & \multicolumn{2}{|c|}{ Holo-SyInrS Ni(II) Bound Model } \\
\hline & $\mathrm{H} 21(\mathrm{~N} \delta)-\mathrm{H} 78(\mathrm{~N} \varepsilon)$ & $\mathrm{H} 21(\mathrm{~N} \varepsilon)-\mathrm{H} 78(\mathrm{~N} \varepsilon)$ \\
\hline Most favoured & $94.2 \%$ & $90.7 \%$ \\
\hline Additionally allowed & $5.8 \%$ & $9.3 \%$ \\
\hline Generously allowed & - & - \\
\hline Disallowed & - & - \\
\hline G-factor & 0.09 & 0.00 \\
\hline
\end{tabular}

Taken together, the analysis of the nickel coordination geometry and of the structural parameters

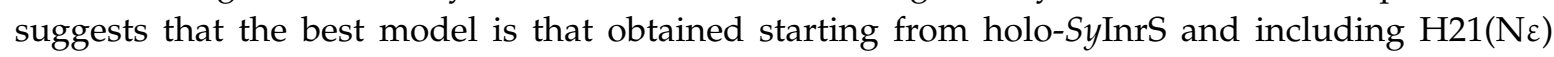
and H78(N $\delta$ ) as nickel ligands (Figure 5). This results suggest that, as observed for FrmR [12], a conformational transition is necessary to achieve the correct $\mathrm{Ni}$ (II)-induced crosslink between two SyIrnS monomers at the interface between the C-terminal of $\alpha$-helix $\alpha 1$ of one monomer and Cys53 located at the $\mathrm{N}$-terminal of $\alpha$-helix $\alpha 3$ of the interacting monomer.

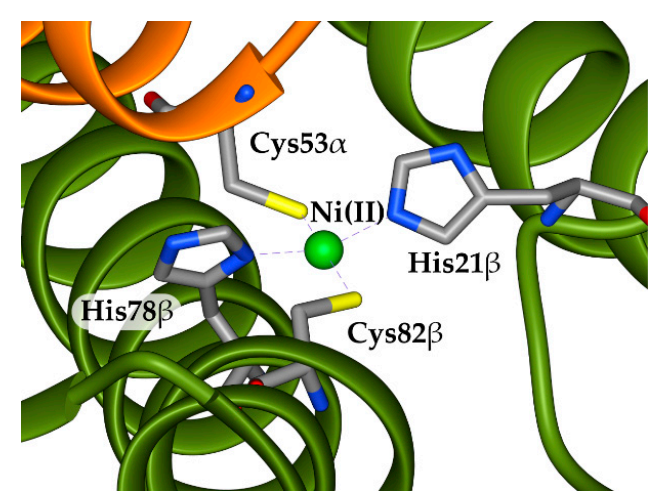

Figure 5. Results for the $\mathrm{H} 21(\mathrm{~N} \varepsilon)-\mathrm{H} 78(\mathrm{~N} \delta)$ modelling of $\mathrm{Ni}(\mathrm{II})$ bound SyInrS starting from the protein in the holo conformation. The SyInrS backbone is reported as ribbons coloured by polypeptide chains, with chain $\alpha$ in orange and chain $\beta$ in green. Putative metal binding residues are reported as sticks coloured according to atom types. The $\mathrm{Ni}(\mathrm{II})$ ion is shown as a green sphere. 


\section{Materials and Methods}

The three missing residues (His19, Val20 and His21) at the N-terminal in chain $\alpha$ and $\alpha^{\prime}$ of apo-SyInrS crystal structure (PDB id: 5FMN [17]) were modelled using Modeller v9.18 [32] and chains $\beta$ and $\beta^{\prime}$ of the same structure as template. The model structure of tetrameric apo-SyInrS in the putative $\mathrm{Ni}(\mathrm{II})$-bound conformation was generated using the same procedure and considering the available crystal structures of $\mathrm{Cu}(\mathrm{I})$-bound CsoR from Geobacillus thermodenitrificans NG80-2 and Mycobacterium tuberculosis as templates (Figure S1, PDB id: 4M1P [8] and 2HH7 [7], respectively). See Figure 1 for the PROMALS3D [19] multiple sequence alignment used in the latter modelling. In both cases, 100 models were generated [32]. Symmetry restraints were also applied in the calculation in order to obtain four symmetrically identical monomers. The best model was selected on the basis of the lowest value of the DOPE score in Modeller v9.18 [33] and the analysis performed with PROCHECK [24] and QMEAN [25].

The Ni(II) bound form of both models was generated in a subsequent modelling stage by including four $\mathrm{Ni}$ (II) ions in the model (one per subunit), in agreement with the metal content analyses carried out in previous studies [6]. The van der Waals parameters for $\mathrm{Ni}$ (II) were derived from the $\mathrm{Zn}$ (II) parameters included in the CHARMM22 force field [34] implemented in the Modeller v9.18 package by applying a scale factor of 1.12 calculated on the basis of the $\mathrm{Ni}$ (II) ionic radius. In all modelling calculations that included $\mathrm{Ni}$ (II) ions, constraints were imposed using a Gaussian-shaped energy potential for distances, angles, and dihedrals in order to correctly position the $\mathrm{Ni}$ (II) ions with respect to the experimentally identified ligated residues (see Table 2). As in the previous modelling stage, symmetry restraints were applied, and the best model was selected on the basis of the lowest value of the DOPE score. A loop optimization routine was used to refine the regions that showed higher than average energy as calculated using the DOPE score. The molecular surfaces and graphics of SyInrS structures, together with analysis of the Ni(II) sites, were performed using the UCSF Chimera package [31] (see Supplementary Material for additional details). The study of the inter-chain interactions was performed by using PDBsum $[27,28]$.

\section{Conclusions}

The results obtained in this study indicate that is it possible to successfully model a SyInrS structure able to bind $\mathrm{Ni}(\mathrm{II})$ ions in a square planar geometry, and that the structure of apo-SyInrS is not sufficient for such modelling. Thus, a quaternary structure rearrangement is necessary for metal binding upon shifting from the apo- to the holo-form of the protein. This result agrees with what has been proposed for other members of the RcnR/CsoR family $[8,9,12,20,22,35]$. The cross-link between two monomer chains occurring at the dimer interface appears to stabilize a specific protein conformation, interfering with the capability of SyInrS to bind the DNA. In particular, a rearrangement of surface charges upon metal binding appears to disfavour the DNA binding conformer in the case of CsoR $[20,22]$ and FrmR [12]. It could be envisaged that also nickel sensors belonging to the RcnR/CsoR family are able to adopt an analogue strategy. The mechanism by which the Ni(II) ion interacts with SyInrS, which in principle can occur through an induced fit mechanism, a conformation selection in solution, or a combination of both, is far from being fully understood. To this aim, InrS and the other members of the RcnR/CsoR family can be interesting targets for further computational studies aimed to the exploration of the conformational space of these proteins through molecular dynamics techniques, as recently proposed by some of us [36]. On the other hand, the study of the $\mathrm{Ni}$ (II) bound form of SyInrS requires the development of specific force field parameters able to model a $\mathrm{Ni}$ (II) ion in the square planar coordination. In recent years the improvement of the computational capabilities and the development of accelerated sampling techniques for molecular simulations $[37,38]$ have made available the tools for the exploration of large conformational changes at the atomistic level [39-41]. In the case of metalloproteins, the use of accelerated sampling techniques requires the use of ad hoc designed force field parameters for the metal ions, able to reproduce structural, thermodynamic, and kinetic observables [42]. 
Finally, the modelling of the apo-SyInrS/DNA complex and the characterization of the sensor-nucleic acid interface can also be useful for the development of new molecules able to interfere with the formation of the protein/DNA complex. This requires the identification of the $n r s D$ operator region and can be done for instance through the use of hydroxyl radical foot-printing essays and opportune knowledge-based docking protocols [43-45]. Some of us already applied this technique in the case of two other metal-dependent transcriptional regulators from the human pathogen H. pylori: Fur, a sensor able to repress the transcription of both Fe(II)-repressible and Fe(II)-inducible promoters [46], and $\mathrm{NikR}$, a $\mathrm{Ni}(\mathrm{II})$-responsive sensor repressing or activating genes that code for $\mathrm{Ni}$ (II) enzymes and for proteins involved in nickel homeostasis [47].

Supplementary Materials: The following are available online at http://www.mdpi.com/2304-6740/7/6/76/s1. Figure S1: RcnR/CsoR family solved structures. Figure S2: Ribbon diagram and inertia ellipsoid of SyInrS in the apo and holo conformations. Figure S3: Detail of the $\alpha$-helices $\alpha 1$ and $\alpha 2$ rotation occurring during the apo to holo conformational transition. Figures S4 and S5: Results for the modelling of Ni(II) bound SyInrS starting from the protein in the apo and holo conformation, respectively. Table S1: CsoR/RcnR family representative sequences. Tables S2 and S3: Structural analysis of the models of Ni(II) bound SyInrS generated starting from the protein in the apo and holo conformation, respectively.

Author Contributions: Conceptualization, F.M.; methodology, F.M.; investigation, E.B.; formal analysis, E.B. and F.M.; writing-original draft preparation, F.M.; data curation, F.M.; resources, F.M.; writing-review and editing, F.M.; visualization, E.B. and F.M.; supervision, F.M.; project administration, F.M.

Funding: This research received no external funding.

Acknowledgments: The Department of Pharmacy and Biotechnology of the University of Bologna is acknowledged for financial support.

Conflicts of Interest: The authors declare no conflict of interest.

\section{Abbreviations}

The following abbreviations are used in this manuscript:

NTA: Nitrilotriacetic acid $\left(2,2^{\prime}, 2^{\prime \prime}\right.$-Nitrilotriacetic acid)

EGTA: Ethylene glycol-bis(2-aminoethylether)- $N, N, N^{\prime}, N^{\prime}$-tetraacetic acid

EDTA: Ethylenediaminetetraacetic acid $\left(2,2^{\prime}, 2^{\prime \prime}, 2^{\prime \prime \prime}\right.$-(Ethane-1,2-diyldinitrilo)tetraacetic acid)

\section{References}

1. Zamble, D.; Rowińska-Żyrek, M.; Kozlowski, H. The Biological Chemistry of Nickel; The Royal Society of Chemistry: London, UK, 2017; Volume 10, pp. 1-380.

2. Organization, W.H. Global Priority List of Antibiotic-Resistant Bacteria to Guide Research, Discovery, and Development of New Antibiotics. Available online: https://www.who.int/medicines/publications/globalpriority-list-antibiotic-resistant-bacteria/en/ (accessed on 27 January 2017).

3. Huertas, M.J.; Lopez-Maury, L.; Giner-Lamia, J.; Sanchez-Riego, A.M.; Florencio, F.J. Metals in cyanobacteria: Analysis of the copper, nickel, cobalt and arsenic homeostasis mechanisms. Life (Basel) 2014, 4, 865-886. [CrossRef] [PubMed]

4. Foster, A.W.; Patterson, C.J.; Pernil, R.; Hess, C.R.; Robinson, N.J. Cytosolic Ni(II) sensor in cyanobacterium: Nickel detection follows nickel affinity across four families of metal sensors. J. Biol. Chem. 2012, 287, 12142-12151. [CrossRef] [PubMed]

5. Zambelli, B.; Musiani, F.; Ciurli, S. Metal ion-mediated DNA-protein interactions. Met. Ions Life Sci. 2012, 10, 135-170. [PubMed]

6. Musiani, F.; Zambelli, B.; Bazzani, M.; Mazzei, L.; Ciurli, S. Nickel-responsive transcriptional regulators. Metallom. Integr. Biometal Sci. 2015, 7, 1305-1318. [CrossRef] [PubMed]

7. Liu, T.; Ramesh, A.; Ma, Z.; Ward, S.K.; Zhang, L.; George, G.N.; Talaat, A.M.; Sacchettini, J.C.; Giedroc, D.P. CsoR is a novel Mycobacterium tuberculosis copper-sensing transcriptional regulator. Nat. Chem. Biol. 2007, 3, 60-68. [CrossRef] 
8. Chang, F.M.; Coyne, H.J.; Cubillas, C.; Vinuesa, P.; Fang, X.; Ma, Z.; Ma, D.; Helmann, J.D.; Garcia-de los Santos, A.; Wang, Y.X.; et al. Cu(I)-mediated allosteric switching in a copper-sensing operon repressor (CsoR). J. Biol. Chem. 2014, 289, 19204-19217. [CrossRef]

9. Higgins, K.A.; Giedroc, D. Insights into protein allostery in the CsoR/RcnR family of transcriptional repressors. Chem. Lett. 2014, 43, 20-25. [CrossRef]

10. Capdevila, D.A.; Edmonds, K.A.; Giedroc, D.P. Metallochaperones and metalloregulation in bacteria. Essays Biochem. 2017, 61, 177-200. [CrossRef]

11. Herring, C.D.; Blattner, F.R. Global transcriptional effects of a suppressor tRNA and the inactivation of the regulator frmR. J. Bacteriol. 2004, 186, 6714-6720. [CrossRef]

12. Denby, K.J.; Iwig, J.; Bisson, C.; Westwood, J.; Rolfe, M.D.; Sedelnikova, S.E.; Higgins, K.; Maroney, M.J.; Baker, P.J.; Chivers, P.T.; et al. The mechanism of a formaldehyde-sensing transcriptional regulator. Sci. Rep. 2016, 6, 38879. [CrossRef]

13. Grossoehme, N.; Kehl-Fie, T.E.; Ma, Z.; Adams, K.W.; Cowart, D.M.; Scott, R.A.; Skaar, E.P.; Giedroc, D.P. Control of copper resistance and inorganic sulfur metabolism by paralogous regulators in Staphylococcus aureus. J. Biol. Chem. 2011, 286, 13522-13531. [CrossRef]

14. Luebke, J.L.; Shen, J.; Bruce, K.E.; Kehl-Fie, T.E.; Peng, H.; Skaar, E.P.; Giedroc, D.P. The CsoR-like sulfurtransferase repressor (CstR) is a persulfide sensor in Staphylococcus aureus. Mol. Microbiol. 2014, 94, 1343-1360. [CrossRef] [PubMed]

15. Chivers, P.T. Nickel Regulation. In The Biological Chemistry of Nickel; The Royal Society of Chemistry: London, UK, 2017; pp. 259-283.

16. Foster, A.W.; Pernil, R.; Patterson, C.J.; Robinson, N.J. Metal specificity of cyanobacterial nickel-responsive repressor InrS: Cells maintain zinc and copper below the detection threshold for InrS. Mol. Microbiol. 2014, 92, 797-812. [CrossRef] [PubMed]

17. Foster, A.W.; Pernil, R.; Patterson, C.J.; Scott, A.J.P.; Pålsson, L.-O.; Pal, R.; Cummins, I.; Chivers, P.T.; Pohl, E.; Robinson, N.J. A tight tunable range for Ni(II) sensing and buffering in cells. Nat. Chem. Biol. 2017, 13, 409. [CrossRef] [PubMed]

18. Carr, C.E.; Foster, A.W.; Maroney, M.J. An XAS investigation of the nickel site structure in the transcriptional regulator InrS. J. Inorg. Biochem. 2017, 177, 352-358. [CrossRef] [PubMed]

19. Pei, J.; Kim, B.H.; Grishin, N.V. PROMALS3D: A tool for multiple protein sequence and structure alignments. Nucl. Acids Res. 2008, 36, 2295-2300. [CrossRef]

20. Tan, B.G.; Vijgenboom, E.; Worrall, J.A. Conformational and thermodynamic hallmarks of DNA operator site specificity in the copper sensitive operon repressor from Streptomyces lividans. Nucl. Acids Res. 2014, 42, 1326-1340. [CrossRef]

21. Chang, F.M.; Lauber, M.A.; Running, W.E.; Reilly, J.P.; Giedroc, D.P. Ratiometric pulse-chase amidination mass spectrometry as a probe of biomolecular complex formation. Anal. Chem. 2011, 83, 9092-9099. [CrossRef]

22. Porto, T.V.; Hough, M.A.; Worrall, J.A. Structural insights into conformational switching in the copper metalloregulator CsoR from Streptomyces lividans. Acta Crystallogr. D 2015, 71, 1872-1878. [CrossRef]

23. Chang, F.M.; Martin, J.E.; Giedroc, D.P. Electrostatic occlusion and quaternary structural ion pairing are key determinants of $\mathrm{Cu}(\mathrm{I})$-mediated allostery in the copper-sensing operon repressor (CsoR). Biochemistry 2015, 54, 2463-2472. [CrossRef]

24. Laskowski, R.A.; MacArthur, M.W.; Moss, D.S.; Thornton, J.M. PROCHECK: A program to check the stereochemical quality of protein structures. J. Appl. Crystallogr. 1993, 26, 283-291. [CrossRef]

25. Benkert, P.; Biasini, M.; Schwede, T. Toward the estimation of the absolute quality of individual protein structure models. Bioinformatics 2011, 27, 343-350. [CrossRef] [PubMed]

26. Baker, N.A.; Sept, D.; Joseph, S.; Holst, M.J.; McCammon, J.A. Electrostatics of nanosystems: application to microtubules and the ribosome. Proc. Natl. Acad. Sci. USA 2001, 98, 10037-10041. [CrossRef] [PubMed]

27. Laskowski, R.A.; Hutchinson, E.G.; Michie, A.D.; Wallace, A.C.; Jones, M.L.; Thornton, J.M. PDBsum: A web-based database of summaries and analyses of all PDB structures. Trends. Biochem. Sci. 1997, 22, 488-490. [CrossRef]

28. Laskowski, R.A.; Jablonska, J.; Pravda, L.; Varekova, R.S.; Thornton, J.M. PDBsum: Structural summaries of PDB entries. Protein Sci. 2018, 27, 129-134. [CrossRef] [PubMed] 
29. Carr, C.E.; Musiani, F.; Huang, H.T.; Chivers, P.T.; Ciurli, S.; Maroney, M.J. Glutamate ligation in the Ni(II)and Co(II)-responsive Escherichia coli transcriptional regulator, RcnR. Inorg. Chem. 2017, 56, 6459-6476. [CrossRef]

30. Martin-Diaconescu, V.; Bellucci, M.; Musiani, F.; Ciurli, S.; Maroney, M.J. Unraveling the Helicobacter pylori UreG zinc binding site using X-ray absorption spectroscopy (XAS) and structural modeling. J. Biol. Inorg. Chem. 2012, 17, 353-361. [CrossRef]

31. Pettersen, E.F.; Goddard, T.D.; Huang, C.C.; Couch, G.S.; Greenblatt, D.M.; Meng, E.C.; Ferrin, T.E. UCSF Chimera-A visualization system for exploratory research and analysis. J. Comput. Chem. 2004, 25, 1605-1612. [CrossRef]

32. Marti-Renom, M.A.; Stuart, A.C.; Fiser, A.; Sanchez, R.; Melo, F.; Sali, A. Comparative protein structure modeling of genes and genomes. Annu. Rev. Biophys. Biomol. Struct. 2000, 29, 291-325. [CrossRef]

33. Shen, M.Y.; Sali, A. Statistical potential for assessment and prediction of protein structures. Protein Sci. 2006, 15, 2507-2524. [CrossRef]

34. MacKerell, A.D.; Bashford, D.; Bellott, M.; Dunbrack, R.L.; Evanseck, J.D.; Field, M.J.; Fischer, S.; Gao, J.; Guo, H.; Ha, S.; et al. All-atom empirical potential for molecular modeling and dynamics studies of proteins. J. Phys. Chem. B 1998, 102, 3586-3616. [CrossRef] [PubMed]

35. Huang, H.T.; Bobst, C.E.; Iwig, J.S.; Chivers, P.T.; Kaltashov, I.A.; Maroney, M.J. Co(II) and Ni(II) binding of the Escherichia coli transcriptional repressor RcnR orders its $\mathrm{N}$ terminus, alters helix dynamics, and reduces DNA affinity. J. Biol. Chem. 2018, 293, 324-332. [CrossRef] [PubMed]

36. Sala, D.; Musiani, F.; Rosato, A. Application of molecular dynamics to the investigation of metalloproteins involved in metal homeostasis. Eur. J. Inorg. Chem. 2018, 2018, 4661-4677. [CrossRef]

37. Bernardi, R.C.; Melo, M.C.R.; Schulten, K. Enhanced sampling techniques in molecular dynamics simulations of biological systems. Biochim. Biophys. Acta 2015, 1850, 872-877. [CrossRef] [PubMed]

38. Mori, T.; Miyashita, N.; Im, W.; Feig, M.; Sugita, Y. Molecular dynamics simulations of biological membranes and membrane proteins using enhanced conformational sampling algorithms. Biochim. Biophys. Acta 2016, 1858, 1635-1651. [CrossRef] [PubMed]

39. Orozco, M. A theoretical view of protein dynamics. Chem. Soc. Rev. 2014, 43, 5051-5066. [CrossRef] [PubMed]

40. Yang, L.Q.; Sang, P.; Tao, Y.; Fu, Y.X.; Zhang, K.Q.; Xie, Y.H.; Liu, S.Q. Protein dynamics and motions in relation to their functions: Several case studies and the underlying mechanisms. J. Biomol. Struct. Dyn. 2014, 32, 372-393. [CrossRef] [PubMed]

41. Chang, C.A.; Huang, Y.M.; Mueller, L.J.; You, W. Investigation of structural dynamics of enzymes and protonation states of substrates using computational tools. Catalysts 2016, 6, 82. [CrossRef] [PubMed]

42. Masetti, M.; Musiani, F.; Bernetti, M.; Falchi, F.; Cavalli, A.; Ciurli, S.; Recanatini, M. Development of a multisite model for $\mathrm{Ni}(\mathrm{II})$ ion in solution from thermodynamic and kinetic data. J. Comput. Chem. 2017, 38, 1834-1843. [CrossRef]

43. Van Dijk, M.; van Dijk, A.D.; Hsu, V.; Boelens, R.; Bonvin, A.M. Information-driven protein-DNA docking using HADDOCK: It is a matter of flexibility. Nucl. Acids Res. 2006, 34, 3317-3325. [CrossRef]

44. Van Dijk, M.; Bonvin, A.M. Pushing the limits of what is achievable in protein-DNA docking: Benchmarking HADDOCK's performance. Nucl. Acids Res. 2010, 38, 5634-6547. [CrossRef] [PubMed]

45. Musiani, F.; Ciurli, S. Evolution of macromolecular docking techniques: The case study of nickel and iron metabolism in pathogenic bacteria. Molecules 2015, 20, 14265-14292. [CrossRef] [PubMed]

46. Agriesti, F.; Roncarati, D.; Musiani, F.; Del Campo, C.; Iurlaro, M.; Sparla, F.; Ciurli, S.; Danielli, A.; Scarlato, V. FeON-FeOFF: The Helicobacter pylori Fur regulator commutates iron-responsive transcription by discriminative readout of opposed DNA grooves. Nucl. Acids Res. 2014, 42, 3138-3151. [CrossRef] [PubMed]

47. Mazzei, L.; Dobrovolska, O.; Musiani, F.; Zambelli, B.; Ciurli, S. On the interaction of Helicobacter pylori NikR, a $\mathrm{Ni}(\mathrm{II})$-responsive transcription factor, with the urease operator: in solution and in silico studies. J. Biol. Inorg. Chem. 2015, 20, 1021-1037. [CrossRef] [PubMed]

(C) 2019 by the authors. Licensee MDPI, Basel, Switzerland. This article is an open access article distributed under the terms and conditions of the Creative Commons Attribution (CC BY) license (http://creativecommons.org/licenses/by/4.0/). 